\title{
RESEARCH OF THE PHYSICAL AND CHEMICAL PROPERTIES AND METHODS OF RED RICE (FOOD COLOUR) DETERMINATION IN SAUSAGE PRODUCTS
}

\author{
Natalia V. Rudometova, Irina S. Kim \\ All-Russia Research Institute for Food Additives - Branch of V. M. Gorbato Federal Research Center \\ for Food Systems of RAS, St. Petersburg, Russia
}

\begin{abstract}
Keywords: food colours, monascus, red rice, sausage products, extraction, thin layer chromatography, high performance liquid chromatography, identification, spectrophotometric analysis

Abstract

In Russia, in the production of meat and sausage products, the food colour, named as Red rice, is use. Red rice is obtain by the cultivation the strains of the Monascus fungus on various carbohydrate substrates, for example rice. That Red rice may contain the mycotoxin citrinin, but neither the purity of the food colour nor the safety profile are regulated. The aim of this work was to study the physical and chemical properties of Red rice and to develop method for its determination in sausage products. The experiments were carried out on model and commercial samples of sausages. The samples were analyzed using spectrophotometry and highefficiency planar and liquid chromatography. Spectrophotometric analysis revealed differences in solubility, coloring power, spectral characteristics, composition and ratio of pigments in commercial samples of Red rice. The extraction parameters of colouring substances from sausages model samples were determined. It has been established that Red rice is extracted with chloroform, acetone, ethanol and its aqueous solutions. Petroleum ether was proposed for degreasing sausages. Red rice from sausages was extracted with acetone because it did not extract synthetic colours and carminic acid. It was found, that 90\% of Red rice is extracted from samples of sausages by double extraction with ultrasonic treatment with a power of $128 \mathrm{~W}$. High performance thin layer chromatography method and high performance liquid chromatography method for the Red rice identification was proposed. The content of Red rice in the extracts was determined by spectrophotometric method. The developed method for the determination of Red rice was tested on commercial samples of sausage products.
\end{abstract}

\section{Introduction}

The current situation on the Russian market is characterizing by a significant amount of falsified food products and various food additives, including colours [1]. Most food colours are xenobiotics, therefore, it is necessary to control the use of colors in food production for safety reasons. In Russia red food colours Red rice, Carmines E120 and Ponceau 4R E124 are used in production of some meat and sausage products [2].

Red rice is obtained by fermenting various carbohydrate substrates, most often rice, by the strains of the fungus Monascus, which produce yellow and red substances: $\mathrm{C}_{21} \mathrm{H}_{26} \mathrm{O}_{5}$ (Monascine), $\mathrm{C}_{23} \mathrm{H}_{30} \mathrm{O}_{5}$ (Ankaflavine), $\mathrm{C}_{21} \mathrm{H}_{22} \mathrm{O}_{5}$ (Rubropunctatine), $\mathrm{C}_{23} \mathrm{H}_{26} \mathrm{O}_{5}$ (Monascorubine), $\mathrm{C}_{21} \mathrm{H}_{23} \mathrm{O}_{4} \mathrm{~N}$ (Rubropunctamine) and $\mathrm{C}_{23} \mathrm{H}_{27} \mathrm{O}_{4} \mathrm{~N}$ (Monascorubramine), whose structural formulas are shown in Figure $1[3,4]$.

Various genus of the Monascus are used to obtain the colour: Monascus purpureus, Monascus pilosus, Monascus anka and Monascus ruber. The strain-producer and the conditions of its cultivation affect the content and composition of colour substances. But technical information about Monascus colours production is a commercial secret and therefore rarely published [5]. The colours are highly soluble in ethanol and slightly soluble in water. The color of its solutions depends on $\mathrm{pH}$ : orange at $\mathrm{pH}$ $3 \div 4$, red at $\mathrm{pH} 5 \div 6$, purple at $\mathrm{pH} 7 \div 9$. Monascus colour- ing substances are fairly stable in $70 \%$ aqueous solution of ethanol. It is resistant to light, high temperatures and oxidation. Red rice is use in China as a food additive for over 2000 years [6].

It was found that Red rice contains the mycotoxin citrinin [7], but neither the criteria for its purity, nor the safety indicators in TR CU029/2012 are regulated, as well as the method for the determination of this food colours [2]. China is the main manufacturer and supplier of Red rice. However, the current Chinese National Standard does not set a maximum limit for citrinin in pigments produced by Monascus. Extensive testing of Red rice has not been conducted in the USA, but consumers are warned to avoid dietary supplements based on it due to possible myopathy and renal failure [5].

In the European Union the maximum level of citrinine ( $2 \mathrm{mg} / \mathrm{kg}$ ) in Red rice preparations is regulate. This level ensures the possible exposure of citrinine from these drugs to well below the level of its nephrotoxicity $(0.2 \mu \mathrm{g} / \mathrm{kg}$ body weight) [8]. However, the results of Red rice various samples study showed that the content of citrinin can reach $7 \mu \mathrm{g} / \mathrm{kg}$ of the product [9]. Acceptable daily intake of Red rice for humans has not been established. As the uncertainty about the carcinogenicity and genotoxicity of Red rice remains, it was decided to revise its maximum allowable level in foods $[8,10,11]$. 
Rubropunctatine

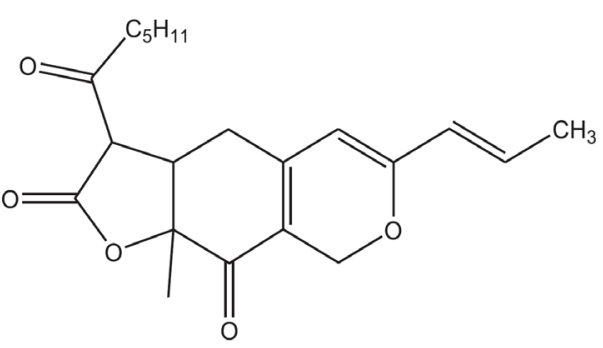

Monascine<smiles>C/C=C/C1=CC2=CC3=C(C(=O)CCCC)C(=O)OC3(C)C(=O)C2=CN1</smiles>

Rubropunctamine<smiles>C/C=C/C1=CC2=CC3=C(C(=O)OCCCC)C(=O)OC3(C)C(=O)C2=CO1</smiles>

Figure 1. The structural formulas of Red rise colouring substances

The inadequate level of researching Red rice, as well as the possibility of falsification, which consists in replacing one colour with another, dictates the need to develop determination methods of colours in food products. The aim of this work was to study the physical and chemical properties of Red rice and to develop method for its determination in sausage products.

\section{Materials and methods}

The objects of the study were commercial samples of food colours Red Rice, Carmines E120, Ponceau 4R E124 and cooked smoked sausages: «Cervelat Muskatny», «Cervelat Konyachny», "Cervelat Gubernsky», which were produced in accordance with the manufacturers' specifications.
Monascorubine<smiles>C/C=C/C1=CC2=CC3=C(C(C)=O)C(=O)OC3(C)C(=O)C2=CO1</smiles>

Ankaflavine<smiles>C/C=C/C1=CC2=CC3=C(C(C)=O)C(=O)OC3(C)C(=O)C2=CN1</smiles>

Monascorubramine

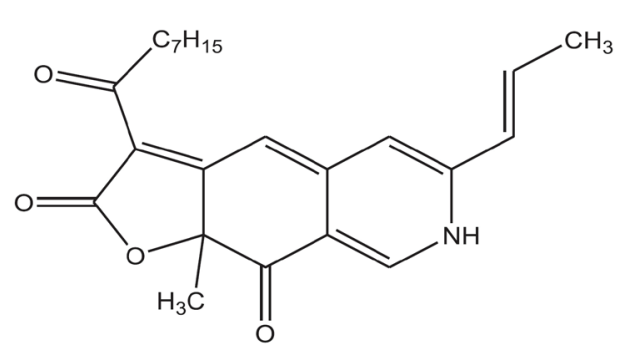

The content of colours in the samples and extracts was determined by measuring the optical density of solutions at the maximums of light absorption at characteristic wavelengths by the spectrophotometric $(\mathrm{SPh})$ method. The measurement was carried out on a SHIMADZU UV-1800 double-beam scanning spectrophotometer in the wavelength range of 300-700 nm against the solvent. Mass fraction of colours in the object of study (in \%) was calculated according to the formulas in the reference source [12]. The colours were identified by high performance thin layer chromatography (HPTLC) method on «Sorbfil» PET sheet plates (Table 1) and high performance liquid chromatography (HPLC) method.

Table 1. Conditions for colours assay by HPTLC method

\begin{tabular}{|c|c|c|c|c|}
\hline \multirow{2}{*}{ № } & \multirow{2}{*}{ Eluent composition, v/v } & \multicolumn{3}{|c|}{ Values Rf for colours } \\
\hline & & Ponceau 4R E124 & Carmines E120 & Red rice \\
\hline 1 & $\begin{array}{l}\text { pyridine: 3-methyl-1-butanol: 2-methylpropanol-1: ethanol: } \\
\text { ammonia } 25 \%(3: 3: 3: 4: 4)\end{array}$ & $0.33 \pm 0.03$ & 0.00 & $\begin{array}{l}0.43 \pm 0.03 \\
0.53 \pm 0.03 \\
0.64 \pm 0.03 \\
0.79 \pm 0.03\end{array}$ \\
\hline 2 & $\begin{array}{l}\text { acetone: ethanol: ammonia } 25 \% \text { : water } \\
\qquad(7: 3: 0.05: 3)\end{array}$ & $0.89 \pm 0.03$ & $\begin{array}{c}0,00 \\
0.49 \div 0.64 \\
0.74 \pm 0.03\end{array}$ & $\begin{array}{l}0.76 \pm 0.03 \\
0.84 \pm 0.03 \\
0.93 \pm 0.03\end{array}$ \\
\hline
\end{tabular}


Also the colours were identified by reverse phase HPLC on a chromatograph VARIAN920 - LC with a diode array detector: column Polaris C8A $150 \times 4.6 \mathrm{~mm}(5 \mu \mathrm{m})$, temperature $28{ }^{\circ} \mathrm{C}$, flow rate $0.6 \mathrm{~cm}^{3} / \mathrm{min}$. Eluent is a mixture of $0.02 \mathrm{M}$ solution of sodium acetate and acetonitrile in a volume ratio of 90:10. Sample volume is $(10 \div 50) \mathrm{mm}^{3}$, detector wavelength at $500 \mathrm{~nm}$, time of analysis is $10 \mathrm{~min}$ utes. The samples were filtered through a filter with a pore diameter of $0.45 \mu \mathrm{m}$. The obtained chromatograms were processed using the GALAXIE program.

Sample preparation for the determination of colours in cooked smoked sausages was carried out in accordance with GOST R ISO 13496-2013. Samples were defatted with chloroform or petroleum ether and centrifuged. The colours were extracted from defatted cooked smoked sausages with constant stirring at a temperature from $20^{\circ} \mathrm{C}$ to $60{ }^{\circ} \mathrm{C}$ and varying the extraction time from 10 to $60 \mathrm{~min}$. Extraction was performed in a stirring device with a rotation speed $120 \mathrm{rpm}$, in a Bandelin Sonorex ultrasonic bath at a power of $128 \mathrm{~W}$ and $160 \mathrm{~W}$, and on a magnetic stirrer

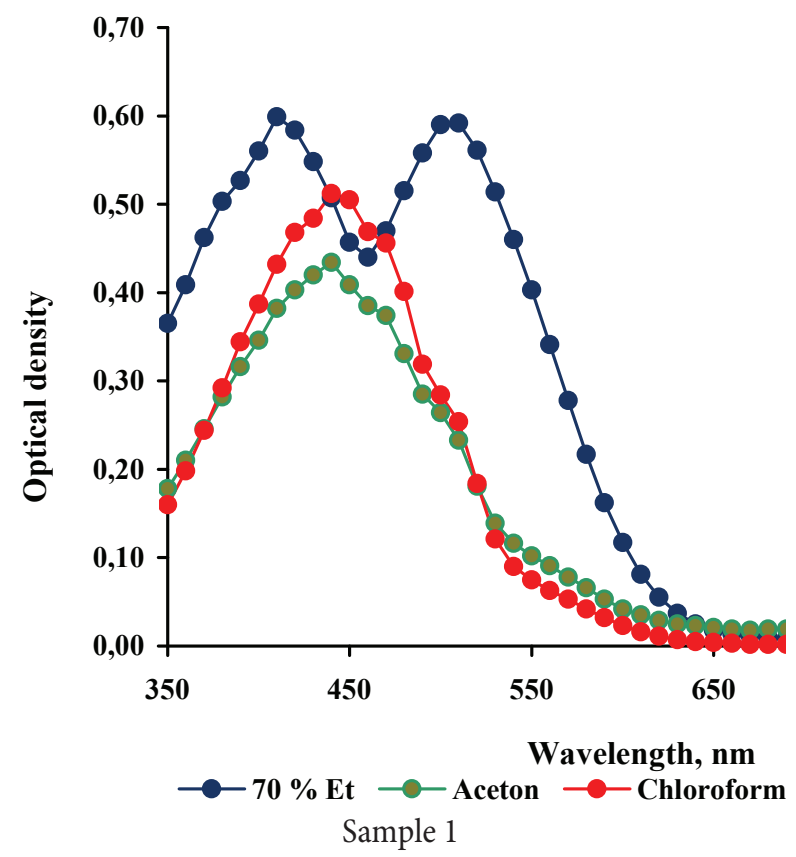

Figure 2. Absorption spectra of different Red rice commercial samples

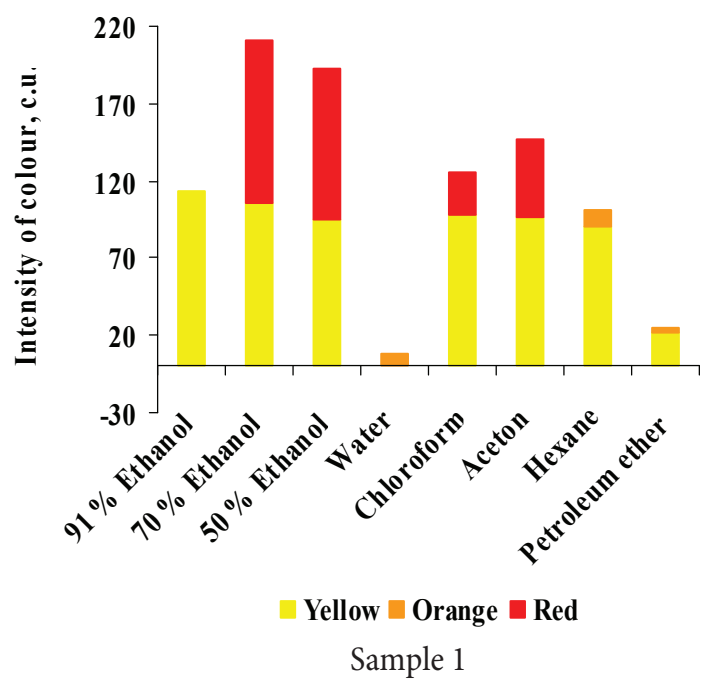

Figure 3. Colour composition of different Red rice commercial samples with a stirrer rotation speed of 400 to $1200 \mathrm{rpm}$. For extraction we used: chloroform, petroleum ether, cyclohexane, hexane, acetone, ethyl alcohol, its aqueous solutions with a mass fraction of ethyl alcohol $50 \%$ and $70 \%$, as well as mixtures of these solvents with the ratio sample: extractant 1:4. The resulting extracts were centrifuged for 15 minutes at $6000 \mathrm{rpm}$. In the supernatant the colours content was determined by the spectrophotometric method.

All experimental measurements were performed three times. Analysis of variance of the obtained data was carried out by Microsoft Excel with a significant difference at $P$ 0.05. Graphical dependencies were obtained using Microsoft Excel software.

\section{Results and discussion}

$\mathrm{SPh}$ analysis of commercial samples of Red rice, carried out in accordance with the method [12], shows that the samples differ in their coloring power, spectral characteristics (Figure 2), composition and quantitative ratio of pigments (Figure 3). The pigment content varied from
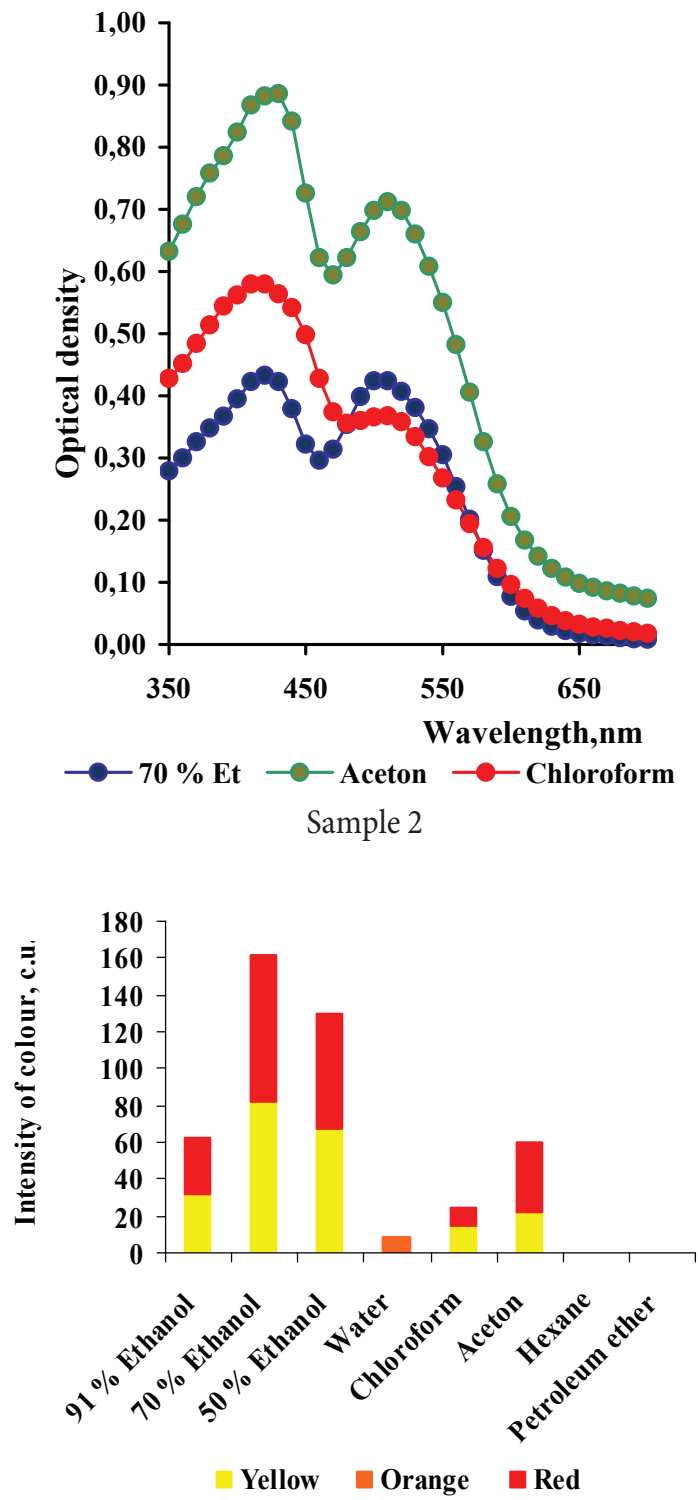

Sample 2 
$(60 \pm 2) \%$ to $(90 \pm 2) \%$. Experiments show that chloroform and acetone extract all of the Red rice coloring substances. Petroleum ether extracts only a small amount of yellow and orange pigments, which will not affect the subsequent identification of the Red rice. Therefore, the petroleum ether is the best for degreasing of the sausages. From the reference source it is known that the isolation of Red rice from various matrices is carried out with water-ethanol solutions at the temperature range from $30^{\circ} \mathrm{C}$ to $60^{\circ} \mathrm{C}[8$, $11,13]$. However, a study of the solubility of colours show, that Carminic acid and Ponceau $4 \mathrm{R}$, as well as Red rice, dissolve in water-ethanol solutions, and these colours have very similar spectral characteristics (Figures 4,5 ).

Carminic acid and Ponceau $4 \mathrm{R}$ is not extracted in acetone, therefore, it was proposed to isolate Red rice from defatted sausages with acetone.

The extraction process of colours was studied on model samples. Analysis of the sample «Cervelat» Muscatny» showed that it does not contain any colours, therefore, model samples were made on its basis. Colours, celite or sodium sulfate, or quartz sand were added to the model samples. Then the sample was triturated until it became homogeneous. It was shown that celite and sodium sulfate was adsorbed colours irreversibly. Therefore, quartz sand was chosen for grinding the samples. It's known, that ultrasonic action is increasing the extraction of different substances from plant and animal matrices $[14,15]$. The results

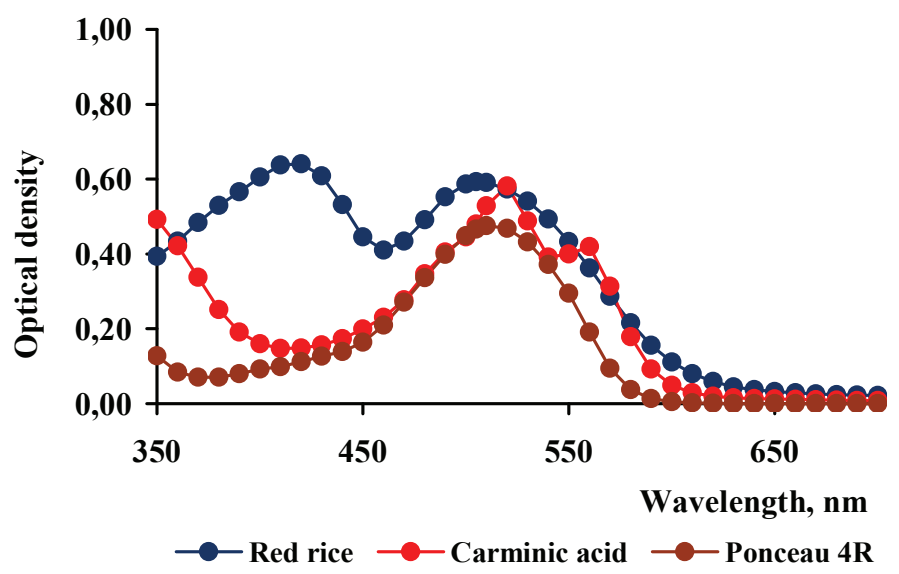

Figure 4. Absorption spectra of colours in 50\% water-ethanol solution

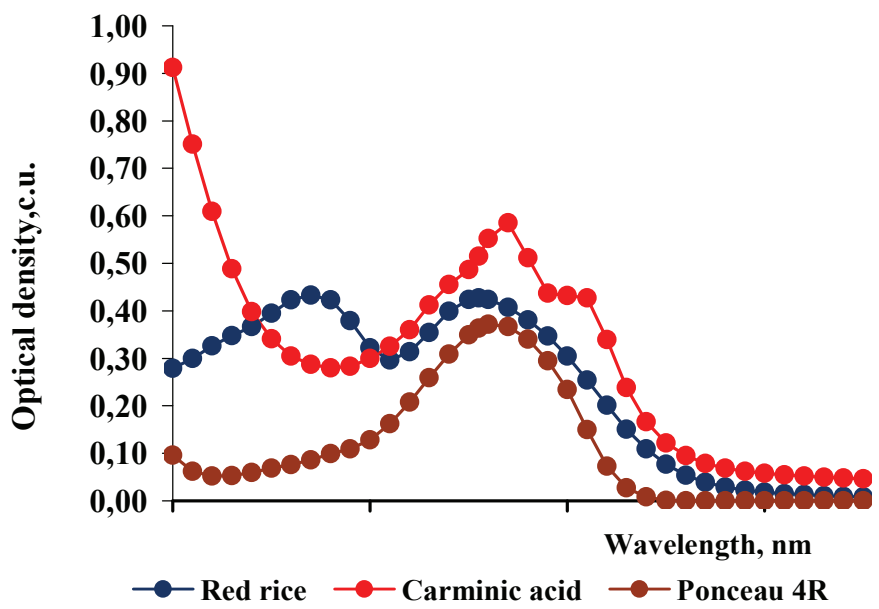

Figure 5. Absorption spectra of colours in 70\% water-ethanol solution
(Figure 6) showed that $90 \%$ of the Red rice was extracted from the samples in two stages of extraction with ultrasonic treatment.

According to the reference sources, the quantitative determination of Red Rice, as a rule, is carried out by $\mathrm{SPh}$ and HPLC methods $[3,4,5,7,8,9,10,16,17,18]$. Based on the results of the identification of colours by HPTLC, two elution systems were selected (Table 1). These eluents correctly identify Red rice in the presence of synthetic colours and Carmine E120 (Figure 7).

According to the experimental data obtained, proposed HPLC method also allows correct identification of colours in sausage products (Figure 8 ). The retention time of the colours was $(4.5 \pm 0.2) \mathrm{min}$ for Carminic acid, for Ponceau $4 \mathrm{R}-(7.3 \pm 0.2) \mathrm{min}$, for Red rice $-(3.3 \pm 0.2) \mathrm{min}$. Thus, the methods of identification of Red rice, Carmines and Ponceau 4R with their possible simultaneous presence in the analyzed sample have been determined.

The developed method was tested on samples of boiled smoked sausages "Cervelat" Konyachny" and "Cervelat "Gubernsky". Food colours Carmine E120 in the amount of $(4.0 \pm 0.4) \mathrm{mg} / \mathrm{kg}$ and Red rice in the amount of $(32 \pm 3) \mathrm{mg} /$ $\mathrm{kg}$ were found in the sample "Cervelat" Konyachny ". No colours were found in the sample "Cervelat" Gubernskiy". Sample analysis results are consistent with the information on the sample label.

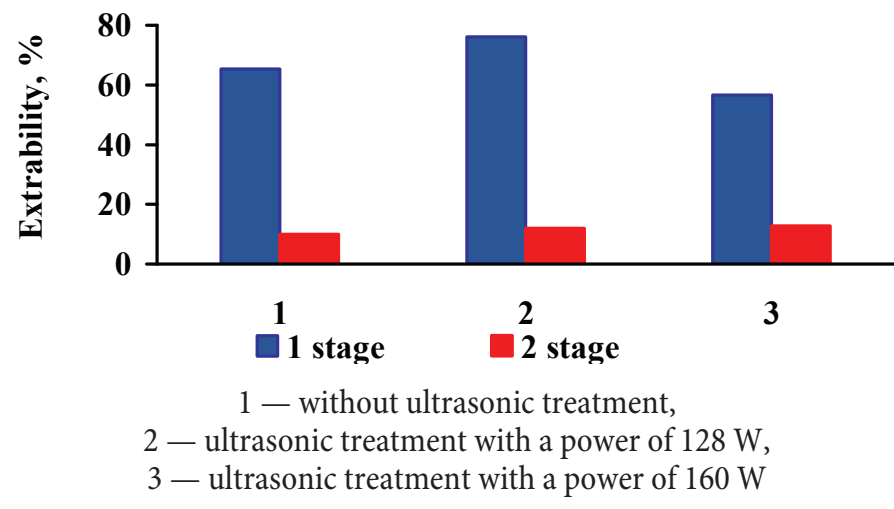

Figure 6. Influence of ultrasonic treatment on the acetone extraction of Red rice from model samples

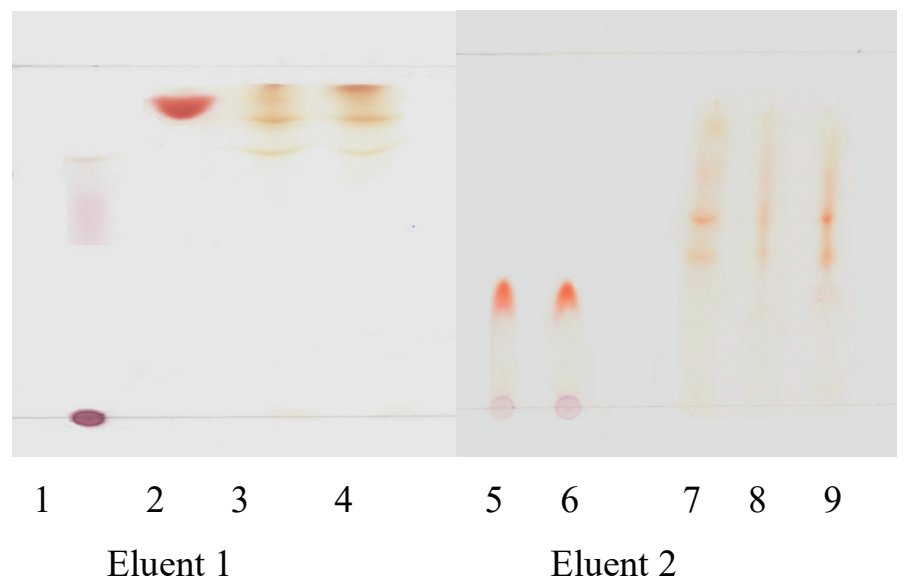

Figure 7. The identification results of Carminic acid (1), Ponceau 4R $(2)$, Red rice $(3,4,7,8,9)$ and a mixture of Carminic acid and Ponceau $4 \mathrm{R}(5,6)$ obtained by HPTLC method 
A

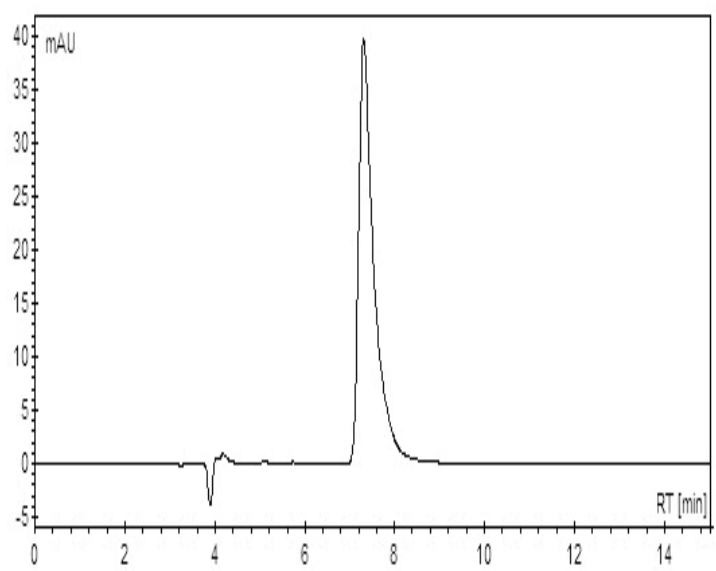

$\mathrm{C}$

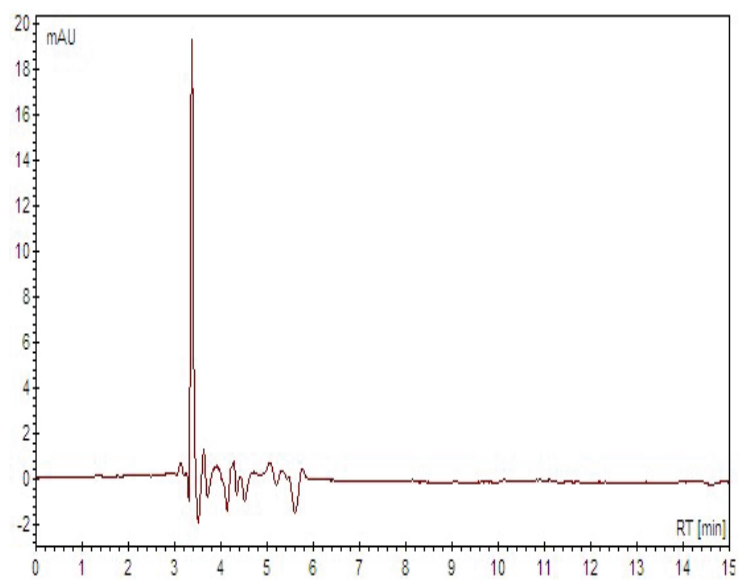

B

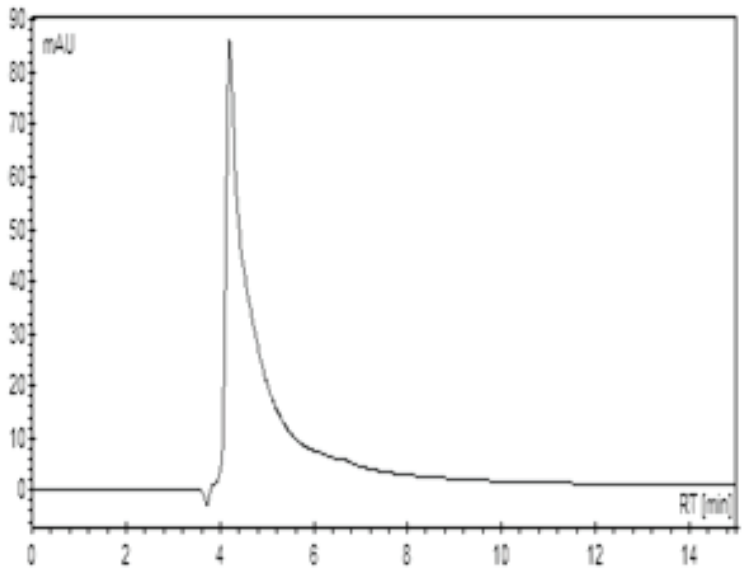

D

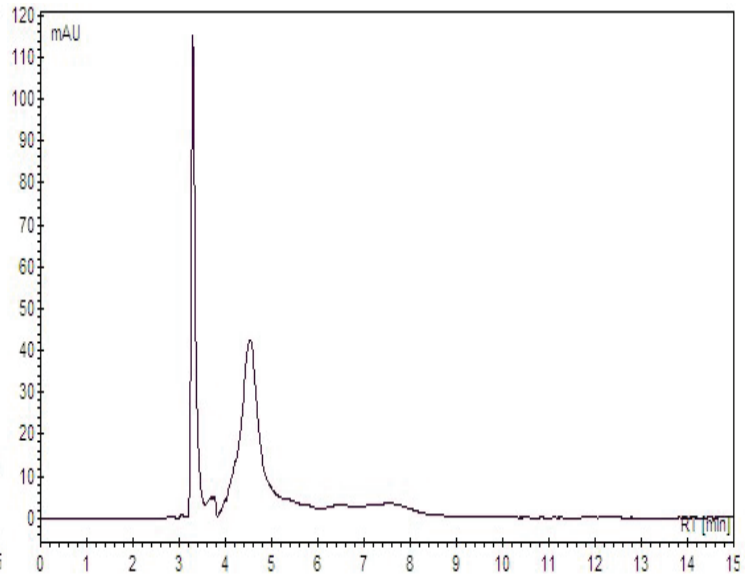

Figure 8. The identification results of Ponceau 4R (A), Carminic acid (B), Red rice (C) and a mixture of Carminic acid and Red rice (D), obtained by HPLC method

\section{Conclusion}

The process of extracting food colors has been studied on model samples of cooked smoked sausages. The extraction parameters of Red rice from sausages are determined. Spectrophotometric analysis revealed differences in solubility, coloring power, spectral characteristics, composition and ratio of pigments in commercial samples of Red rice. It is proposed to use petroleum ether for defatting sausages, and acetone for the extraction of Red rice. Methods of spectrometric and chromatographic analysis have been developed to determine the Red rice in cooked smoked sausages. The developed method was tested on commercial samples of cooked smoked sausages.

\section{REFERENCES}

1. Rudometova, N.V. (2014). Food additives and colorants: methodological support of product safety. Production quality control, 8, 13-19.

2. TR TS029/2012 Customs Union Technical Regulations "Safety requirements of food additives, flavorings and processing aids" [Electronic resource: http://www.eurasiancommission. org/ru/act/texnreg/deptexreg/ tr/Pages/bezopPischDobavok. aspx / Access date 09.09.2020]

3. Agboyibor, C., Kong, W.-b., Chen, D., Zhang, A.-m., Niu, S-q. (2018). Monascus pigments production, composition, bioactivity and its application: A review. Biocatalysis and Agricultural Biotechnology, 16, 433-447. https://doi.org/10.1016/j. bcab.2018.09.012

4. Mhalaskar, S.R., Thorat, S.S., Deshmukh, Y.R. (2017). Standardization of fermentation parameters for the production of food bio-colours through submerged bio-reactor fermentation. Ecology, Environment and Conservation, 23(1), 211-216.

5. Srianta, I., Ristiarini, S., Nugerahani, I., Sen, S. K., Zhang, B. B., Xu, G. R., Blanc, P. J. (2014). Recent research and development of monascus fermentation products. International food research journal, 21(1), 1-12.
6. Hendry, G.A.F., Houghton, J.D. (1996). Natural food colorants. Blackie Academic \& Professional. - 350 p. ISBN978-0-75140231-5, https://doi.org/10.1007/978-1-4615-2155-6

7. Xu, B.-j., Jia, X.-j., Gu, L.-j., Sung, C.-k. (2006). Review on the qualitative and quantitative analysisof the mycotoxin citrinin. Food Control, 17(4), 271-285. https://doi.org/10.1016/j.foodcont.2004.10.012

8. Commission Regulation (EU) № 212/2014 of 6 March 2014 amending Regulation (EC) No 1881/2006 as regards maximum levels of the contaminant citrinin in food supplements based on rice fermented with red yeast Monascus purpureus. (2014). Official Journal of the European Union, 67/3.

9. Priatni, S., Damayanti, S., Saraswaty, V., Ratnaningrum, D., Singgih, M. (2014). The Utilization of Solid Substrates on Monascus Fermentation for Anticholesterol Agent Production. Procedia Chemistry, 9, 34-39. https://doi.org/10.1016/j.proche.2014.05.005 10. Kumari, H. P. M., Naidu, K. A., Vishwanatha, S., Narasimhamurthy, K., Vijayalakshmi, K.G. (2009). Safety evaluation of monascus purpureus red mould rice in albino rats. Food and chemical toxicology, 47(8), 1739-1746. https://doi.org/10.1016/j. fct.2009.04.038 
11. Dikshit, R., Tallapragada, P. (2014). Collective effects of stress on optimization of pigment production by monascus purpureus. Chiang mai journal of science, 41(3), 524-530.

12. Food additives code. Ministry of Food and Drug Safety Regulation (2019). [Electronic resource: http://extwprlegs1.fao.org/ docs/pdf/kor190402.pdf / Access date 09.09.2020.]

13. Velmurugan, P., Kamala-Kannan, S., Balachandar, V., Lakshmanaperumalsamy, P., Chae, J. - C., Oh, B.-T. (2010). Natural pigment extraction from five filamentous fungi for industrial applications and dyeing of leather. Carbohydrate Polymers, 79(2), 262-268. https://doi.org/10.1016/j.carbpol.2009.07.058

14. Kalinina, I.V., Fatkullin, R.I. (2016). Implementation of effects of ultrasonic cavitation influence as a factor of intensification of extraction of functional elements. Bulletin of the South Ural state university. Series: food and biotechnology, 4(1), 64-70.

15. Rudometova, N. V., Kim, I.S. (2019). Capsaicin extraction from hot pepper of capsicum genus. Processes and food produc- tion equipment, 1, 62-73. https://doi.org/10.17586/23101164-2019-12-1-62-73

16. Singgih, M., Saraswaty, V., Ratnaningrum, D., Sri Priatni, S., Damayanti, S. (2014). The influence of temperature and ethanol concentration in monacolin $K$ extraction from monascus fermented rice. Procedia Chemistry, 9, 242-247. https://doi. org/10.1016/j.proche.2014.05.029

17. Liang, B., Du, X.-J., Li, P., Sun, C.-C., Wang, S. (2018). Investigation of Citrinin and Pigment Biosynthesis Mechanisms in Monascus purpureus by Transcriptomic. Frontiers in Microbiology, 9. https://doi.org/10.3389/fmicb.2018.01374

18. Mal'a, P., Baranová, M., Marcinčáková, D., Nagy, J. (2010). Organoleptic evaluation of poultry meat products with wheat protein - seitan, coloured by microbial natural pigment. Assam university journal of science and technology: biological and environmental sciences, 5, 1-5.

\section{AUTHOR INFORMATION}

Natalia V. Rudometova - candidate of chemical sciences, leading research scientist, laboratory of physical and chemical research methods, AllRussia Scientific Research Institution for Food Additives - Branch of V. M. Gorbatov Federal Research Center for Food Systems of RAS, 191014, Sankt-Petersburg, Liteyniy Prospect, 55. Tel.+7-812-272-75-78. E-mail: natrudjob@mail.ru

ORCID: https://orcid.org/0000-0002-9414-6806

* corresponding author

Irina S. Kim - junior research scientist, laboratory of physical and chemical research methods, All-Russia Scientific Research Institution for Food Additives - Branch of V. M. Gorbatov Federal Research Center for Food Systems of RAS, 191014, Sankt-Petersburg, Liteyniy Prospect, 55. Tel.+7-812-272-56-26. E-mail: vniipakk55@mail.ru

All authors bear responsibility for the work and presented data.

All authors made an equal contribution to the work.

The authors were equally involved in writing the manuscript and bear the equal responsibility for plagiarism.

The authors declare no conflict of interest.

Received 09.09.2020 Accepted in revised 06.12.2020 Accepted for publication 20.12.2020 